\title{
A IMAGEM GRÁFICA NO OCIDENTE E A PRODUÇÃO DE SENTIDO NA HISTÓRIA DA CULTURA VISUAL DA ANTROPOLOGIA CRISTÃ
}

Karl Georges Gallao, McS.

Pontifícia Universidade Católica do Rio de Janeiro

karlmuhs@hotmail.com

Alberto Cipiniuk, Dr.

Pontifícia Universidade Católica do Rio de Janeiro

acipiniuk@gmail.com

Resumo: Este artigo é um breve estudo da relação da civilização ocidental com as imagens. A elucidação dos códigos invisíveis daquilo que é visível aos nossos olhos dissipa alguns mitos tenazes, que por sua vez estão legitimados pela perspectiva hegemônica como verdades inalienáveis de um tempo histórico específico, tal como verifica-se no Campo do Design. $\mathrm{Na}$ contemporaneidade tendemos a aceitar as imagens como suportes capazes de transmitir informações de qualquer natureza, pois, acreditamos, que elas carregam uma potência que extrapola a lógica das coisas materiais que dão sentido ou nos fazem compreender o nosso mundo. Daí porque, para alguns, sua capacidade comunicacional sugere funcionar de forma tão dinâmica, podendo ser comparada, confundida ou até que pudesse superar a eloquência das palavras. Portanto, ensejamos sobretudo compreender como o sentido comunicacional produzido e a autoridade conferida às imagens no Ocidente.

Palavras-chave: imagem, imagem religiosa, história, cultura visual, campo do design

\begin{abstract}
This article is a brief study on the relationship Western civilization holds towards imagery. The elucidation of the invisible codes of imagery which is visible to our eyes dissipates some tenacious myths, which are made legitimate by the hegemonic perspective of absolute truths of a specific historical moment, as it is verified in the design field. In contemporaneity, we tend to accept images as supports capable of transmitting information of any nature because we believe them to carry a potency that extrapolates the logic of material things which provide meaning to and make us understand our world. That is why, to some, their communicating capacity suggests functioning in such a dynamic way it could be compared to, mistaken by or even able to overcome the eloquence of words. Therefore, we wish mostly to comprehend the communicational meaning produced and the authority given to imagery in the West.
\end{abstract}

Key words: imagery, religious imagery, history, visual culture, design field. 
Desde muito antes do Concílio de Trento (1545 até 1563) o culto das imagens desempenhava um papel crucial na criação da experiência do sagrado entre os católicos, e julgamos que essa prática social com as imagens, pode ser considerada tão antiga no Brasil quanto sua própria história. O culto das imagens foi essencial para a construção e permanência de uma cultura visual que julgamos ser o principal esteio da forma como hoje encaramos as imagens, a maneira como as produzimos e a razão pela qual continuamos a produzi-las. A complexa relação da civilização ocidental com as imagens, disso que nós encaramos como objetos dotados de valor simbólico e cultural, muito mais do que imagens ou representações das coisas do mundo, sejam ela reais ou imaginadas, contribui sobremaneira como ferramenta para a produção de uma interpretação político-cultural para o Campo do Design gráfico.

Atualmente, em vista de um alargamento exponencial do campo científico de nossa área e da transversalidade dos diferentes saberes com interesses em áreas díspares, julgamos que não apenas os designers, como também historiadores da arte e estudiosos em geral interessados pelas imagens gráficas, estão inclinados para a definição do verdadeiro alcance comunicacional e cognitivo que as imagens podem produzir dentro dos grupos sociais onde elas são empregadas.

Acreditamos que antes de aceitarmos os efeitos duradouros da mudança conceitual sobre as imagens trazidos, em especial, pelo grupo de Aby Warburg - o qual Fritz Saxl e Erwin Panofsky faziam parte -, ou ainda o movimento historiográfico da escola historiográfica francesa dos Annales, seja para a história da arte e, por conseguinte, para o campo epistemológico do design ${ }^{1}$, seria preciso examinar e separar com cuidado as alterações teóricas e metodológicas, da história cultural das imagens. Isto é, entender em que medida a prioridade oferecida legitimamente pelos historiadores e críticos de arte, em geral, contribuiu para distanciar as problemáticas, ao invés de aproximá-las da discussão concreta da imagem revestida pelo tecido social. Essa noção, que julgamos ser de natureza política, seria de extrema relevância para o nosso campo científico no que diz respeito a discussão sobre o entendimento do sentido comunicacional das imagens gráficas a partir de sua aplicação na história da cultura visual do mundo ocidental.

A "história da cultura visual", ou "história cultural das imagens"2 certamente nos renderia outro viés de análise, isto é, um modo a reconstruir as regras ou convenções conscientes ou inconscientes, que reagiriam à percepção e interpretação de imagens em uma determinada cultura. Parte dos conceitos empregados possuiriam suas bases aplicadas ao estudo do passado, a interpretação visual, que, por sua vez, devota atenção aos ícones religiosos e às narrativas. Assim, reforçamos que este artigo apresenta outra possibilidade para intermediar o diálogo entre as teorias da imagem

\footnotetext{
${ }^{1}$ Chamamos atenção para a relação de continuidade entre a corrente tradicionalista formalista da "Grande Tradição" e as teorias que trabalham com a experiência psico fisiológica subjetiva da visão semiótica, estruturalismo, behaviorismo, etc. - que passam a ser adotadas pelas primeiras escolas alemãs de design no início do século XX e que se mantém ainda hoje nas universidades e faculdades que ministram cursos em design como hegemônicas. GALLAO, Karl Georges. Santinhos: uma reflexão entre o design e os impressos religiosos populares. 2012. 140 f. Dissertação (mestrado) - Pontifícia Universidade Católica do Rio de Janeiro, Departamento de Artes e Design, 2012.

${ }^{2}$ BURKE, Peter. Testemunha ocular: história e imagem. Bauru: EDUSC, 2004, p.227.
} 
que constituem o campo teórico do Design - tais como e enfoque semiológico ou o formalismo, enfim -, e a história da cultura visual: que considera o significado das imagens em relação ao contexto social. Talvez, mediante a comparação da história da cultura visual com outras disciplinas que estudam as composições gráficas, sejamos capazes de descobrir em que aspecto uma determinada imagem pode se considerada única dentro das circunstâncias políticas e sociais que regem sua materialidade. Isto pois, consideramos as transformações das estruturas, e para nos auxiliar a compreender as promessas e os perigos de utilizar a evidência visual na escrita da história, entendemos que é necessário submetê-la ao crivo de uma análise mais minuciosas de seus conteúdos subjetivos.

Essa temática, por sua, vez nos aludiria a uma outra compreensão sobre a maneira que veríamos ou perceberíamos as coisas do nosso mundo. Isto é, diríamos que a imagem gráfica ${ }^{3}$ seria compreendida hoje como um artefato material que detém uma potência transcendental, uma autoridade particular, capaz de comunicar tão bem ou melhor do que o texto escrito, daí a famosa frase de que uma imagem vale mais do que dez mil palavras. Todavia, talvez pudéssemos indagar em que medida essa afirmação estaria de acordo com os códigos visuais alocados na própria imagem. Ou ainda, se esses princípios não estariam de acordo com a política de legitimação que giraria em torno de sua materialidade, para que fosse instrumentalizada no domínio e na manutenção do imaginário cultural em diferentes épocas.

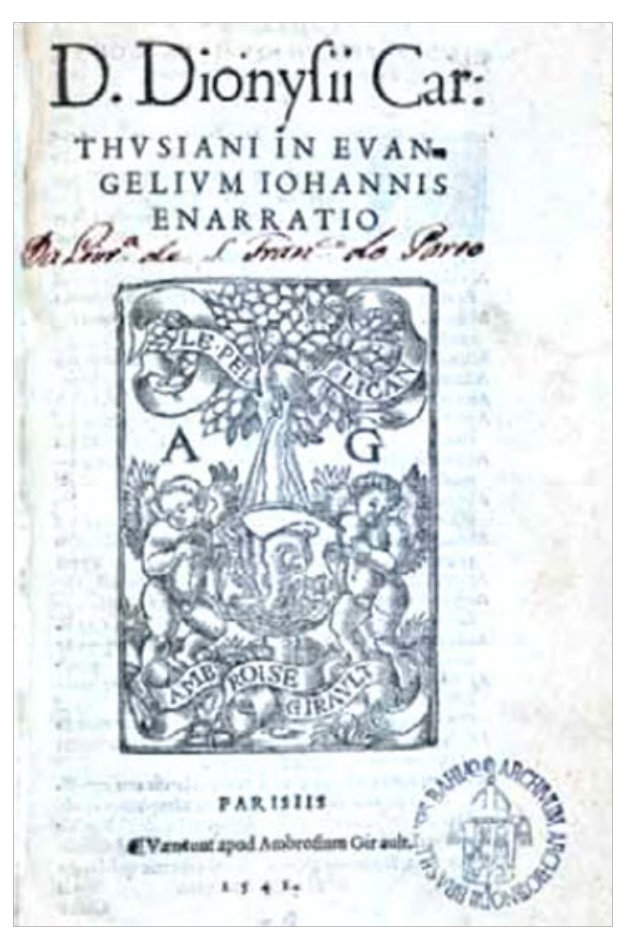

Figura 1 - Frontispício do Evangelium lohannis Enarratio, Don Dionysii Carthusiani, de 1541, adquirido por Don José Andres, na cidade do Porto em Portugal.

Acervo de obras raras da biblioteca do Mosteiro de São Bento, Bahia.

\footnotetext{
${ }^{3}$ Ressaltamos aqui que o termo "imagem gráfica" é específico, pois desejamos deixar consignado em existem outras formas de imagem ou representação, mas que o nosso interesse se dirige para a imagem concreta, física ou material e não a imagem pensada, sonhada ou aquela que emerge silenciosa depois da leitura de uma página escrita.
} 
Assim, para assumirmos a noção de uma política no âmbito da definição teórica das imagens, faz-se necessário uma breve análise histórica de modo a compreendermos. Nesse sentido, examinamos de modo quase antropológico como a cultura religiosa cristã produziu um programa visual e fez uso de seus efeitos de acordo com seus interesses particulares. E, sobretudo, como esses efeitos produzidos perduraram através dos tempos.

De acordo com a história, a configuração formal, a estética, o estilo, a representação ou a forma das primeiras estampas religiosas impressas do continente europeu remontam mais precisamente aos séculos XV e XVI, e até onde temos conhecimento, elas também foram utilizadas como exemplos, junto com pinturas e outros artefatos para a produção de ícones religiosos para a evangelização dos povos ameríndios. Vale ressaltar que o suporte ou meio impresso em papel para distribuição de imagens de modo geral era empregado nas Américas ao mesmo tempo em que fora empregado na Europa para difusão de uma cultura e que no caso da Europa se tratava de imagens científicas oriundas da Revolução Científica ${ }^{4}$, pois a impressão por tipos móveis de Johannes Gutenberg acabava de ser inventada. ${ }^{5}$ Assim, as imagens eram usadas socialmente por um grande número de pessoas e com os mais diferentes propósitos políticos, sendo que o sentido religioso aqui é entendido como parte de uma política religiosa. Sabemos que muitas dessas pequenas recordações avulsas impressas eram destinadas para ilustrar os livros de piedade ou a pequenos oratórios que se perderam no tempo. ${ }^{6}$

Parte desse material consistia de estampas avulsas que faziam parte do material tipográfico volante existente nas oficinas, para serem impressos de acordo com as necessidades editoriais; as estampas eram trabalhadas muitas vezes de modo a serem enquadradas por simples vinhetas ou tarjas, sem qualquer ligação ao arranjo ornamental.

Seria importante explicitar que imagens e textos religiosos foram trabalhados de forma complementar em uma única peça gráfica, de modo que essa estrutura representacional ou configuração impulsionaria a comunicação em nível persuasivo ou retórico, tal como desejavam os padres que participaram do Concílio de Trento. Isto é, mais uma vez lembramos que o impresso religioso é aqui considerado antes de mais nada como uma espécie de ferramenta política de conversão e evangelização.

Embora no Ocidente a imagem venha ser compreendida, depois da Idade Média, como mais contagiosa, mais viral do que o texto escrito, diríamos, em contrapartida, que

\footnotetext{
${ }^{4}$ MARTIN, John Rupert. Baroque. New York: Harper \& Row, Publishers, 1977. p.65-72.

${ }^{5} \mathrm{~A}$ imagem não era mais uma imagem produzida artesanalmente, uma por uma, por um lento processo laborativo manual, mas uma imagem produzida por uma nova tecnologia de produção em série e que ela tinha a ver não com o modo doméstico de produção, mas com o modo de produção industrial, ainda que embrionário.

${ }^{6}$ Sabemos também que no caso de Portugal já havia uma produção organizada e sistematizada sobre esse tipo de material gráfico, ainda que se comparada às novas tecnologias de impressão, mais ou menos primitivas do ponto de vista estilístico ou da configuração. JÚNIOR, Oliveira. O Primeiro impressor português e sua obra. Porto, 1942. In.: SOARES, Ernesto. Retratos, in.: Museu, v. 4, n. 10: Porto, 1945. [BN: BA 3005 V], p. 13.
} 
certos religiosos letrados, devotos da Letra perdida ${ }^{7}$, sentiram um estremecimento diante do retorno das superstições primitivas em relação aos novos usos das imagens. ${ }^{8}$ Hoje, muitos colegas do Campo do Design não chegam a compreender que um texto poder ser empregado sem imagens. ${ }^{9}$

Daí, acreditarmos que um dos principais sustentáculos da colonização ibérica estaria relacionado à revolução dos modos de representação das imagens, mais precisamente na passagem da pictografia à escrita alfabética dentro das culturas autóctones. No México Colonial, por exemplo, os índios haviam sido apresentados à escrita europeia, embora já possuíssem uma forma própria de escritura. A eles, também foram apresentados aos impressos em papel e às placas de madeira, assim não apenas absorveram novos valores a sua cultura, como também alinharam esse sistema de escrituras às suas formas tradicionais voltadas para a produção de imagens, àquelas fundadas nas imagens que empregavam em seus ritos e, do mesmo modo, continuaram empregando o novo programa de cultura visual que vinha da metrópole. No final do século XVI, a dupla natureza desses artefatos impressos (com imagens e textos), impulsionados pela Igreja e pelas correntes humanistas letradas europeias, nos levaria, isto é, levaria os índios, a considerar a remodelagem e a alteração do olhar implicados em registrar as coisas por escrito, e ainda os incitaria a medir o controle comunicacional que os meios indígenas, influenciados pelos impressos europeus, passariam a exercer. Em vista de uma nova ordem visual, ou melhor, de um novo programa da cultura visual ${ }^{10}$, um verdadeiro protocolo para construção das imagens, ousamos dizer que o entendimento das imagens seria quase impossível aos locais, não fosse a presença do texto, que a ela seria invariavelmente associado.

A complementaridade da imagem com o texto corresponderia ao prodígio, ou milagre do santo exaltado. ${ }^{11}$ Os versos em latim, além de outros códigos gráficos religiosos ${ }^{12}$ contidos nas margens e nas tarjas, portanto na configuração formal ou gráfica das imagens, constituiriam os complementos indispensáveis e os prolongamentos taumatúrgicos esperados por aqueles que faziam uso das imagens sagradas impressas. Para os eclesiásticos e os artistas, o verbo e a configuração gráfica ou formal da imagem formariam uma combinação indissolúvel, a ponto de tornar supérflua

\footnotetext{
${ }^{7}$ Falamos dos devotos do texto sagrado - as Escrituras -, autoridade fundamental de uma religião do Livro, assim como toda prática letrada, da qual os clérigos (os litterati) conservaram por séculos seu monopólio.

${ }^{8}$ Estamos nos referindo às menções bíblicas contra o uso das imagens, tal como a passagem de Moisés condenado o culto ao bezerro de ouro.

${ }^{9}$ Tomando por base o livro "Ver é compreender - Design como ferramenta estratégica de negócio" do designer Ricardo de Souza Leite, poderíamos considerar que a própria obra se propõe explicar os conceitos do design e seu papel na sociedade a partir de um catálogo de imagens publicitárias. Como consta na apresentação: "O que este livro proporciona está muito além da informação: é uma experiência de percepção. Suas páginas aqui estão para serem observadas, vividas, consumidas, digeridas. As coisas comunicam. (...)" LEITE, Ricardo de Souza. Ver é compreender: design como ferramenta estratégica de negócio. Rio de Janeiro: Editora Senac, 2003.

10 GRUZINSKI, Serge. A Guerra das imagens: de Cristóvão Colombo a Blade Runner (1492-2019). São Paulo: Companhia das Letras, 2006, p. 165.

${ }^{11}$ GALLAO, op. cit., p. 61.

${ }^{12}$ Cachos de uvas, pelicanos, peixes, conchas, aves do paraíso, querubins, rosas, etc.
} 
qualquer descrição metódica a respeito das representações iconográficas. O Deus do Antigo Testamento fulminava o homem imaginário, mas os adeptos do Novo Testamento não conseguiram, afinal, privar-se de ídolos à moda antiga para inculcar os idólatras à ideia nova do criador único.

Temos aqui um problema teológico no uso das imagens, pois afinal de contas, Deus começa por ser místico e em meio ao processo de expansão da Igreja Apostólica Romana, acaba como político, isto é, envolto pela política idolátrica de propagação das imagens. Num primeiro momento os primeiros representantes da igreja que anunciavam o Reino dos Céus confiaram apenas à Palavra ou ao Verbo: exprimiram-se por símbolos, enigmas e parábolas porque apenas a Voz poderia assoprar o Absoluto, e apenas a linguagem verbal, da cultura letrada europeia poderia extrair um sentido do universo visível. No entanto, os mediadores do Messias que vêm em seguida - os papas e os bispos - reinjetaram a imagem na ideia porque somente ela ofereceria corpo ao Espírito, carne à promessa. De uma forma geral, diríamos que o emprego conjunto de símbolos e insígnias gráficas, acompanhados de suas respectivas legendas ${ }^{13}$ se trata de um fato recorrente no processo de comunicação quando a Palavra ou o texto da verdade engendra a instituição correspondente - seja ela Igreja, Estado ou partido político. Quando a mensagem da Salvação ou da Revolução, no caso político, propagase fora de seu perímetro intelectual de origem, as práticas relativas ao uso da imagem voltam à cena e crescem de modo a satisfazer o desejo da visão. A história nos mostraria que a passagem para a práxis faria com que os defensores da doutrina católica fossem levados a satisfazer uma espécie de libido ótica, onde tudo indica, parece ser comum aos homens. Em outras palavras, a marcha da história nos mostra que existe um processo de maturação sobre a compreensão do sentido ou intencionalidade política contido nas imagens. Sentido esse adquirido através dos tempos pela política religiosa que autorizaria a permissão de sua produção no uso, para que enfim pudesse configurar seu significado, compreendido nos tempos atuais como absoluto em termos de verdade.

$\mathrm{Na}$ literatura existente sobre esse tema, essa associação entre imagem e texto para os católicos é antiga e muito problemática. Afirma-se, de modo geral que desde a Idade Média o papa Gregório o Grande, no ano 600, teria criado a célebre frase de que as imagens eram a "bíblia dos iletrados", pois o papa entendia que elas deveriam servir para ensinar a história religiosa para aqueles que não podiam ler as escrituras e daí a catedral poderia se considerada uma espécie de livro de pedra para os ignorantes. Com isso verifica-se a importância dos vitrais e das pinturas parietais. Ocorre que há um gigantesco equívoco nessa afirmação. Essa antiga noção largamente empregada pelos historiadores da arte ${ }^{14}$, quando eram os únicos responsáveis pelo estudo das imagens, traduz muito mais a noção idealista da estética kantiana, isto é, que seria possível a cognição por intermédio dos sentidos e que em certo sentido, vigora ainda nos dias de hoje, especialmente no Campo do Design, quando os designers gráficos afirmam que uma imagem vale mais do que dez mil palavras. No meio acadêmico a maior parte dos designers acredita que uma imagem comunica de modo puro e sem

13 Por legenda entenda-se: inscrições sejam em medalhas, moedas, emblemas, escudos ou monumentos, letreiros, rótulos, ou dísticos, com um relato da vida ou do martírio de um santo.

${ }^{14}$ MÂLE, Émile. L'Art religieux du Xlle siècle en France. Paris: Ernest Lerox, 1898. 
intermediação de qualquer outra linguagem ou sentido. Basta haver uma "boa" imagem que o observador sabe do que se trata, enfim, os designers acreditam que é possível para os consumidores modernos montar uma estante modulada que chega de uma fábrica desmontada, apenas com um desenho de como ela ficará quando montada. Contudo e, felizmente, pelo menos do ponto de vista teórico, embora o meio acadêmico do Campo do Design ignore, essa noção já foi superada ${ }^{15}$ há algum tempo.

Não há e nunca houve na história visual da cultura cristã do ocidente uma equivalência entre uma imagem e um texto escrito, quando as sutilidades, as significações mais profundas de uma imagem, apenas podem ser alcançadas por aqueles que também são letrados. Ainda hoje - caso fossemos traçar correlações históricas do passado com o nosso mundo visual -, na maioria das vezes, a dificuldade em dar conta da especificidade visual da imagem faz com que ela seja convertida em tema e tratada como fornecedora de informação redutível a um conteúdo verbal específico, isto é, fechado. Ou ainda, em contrapartida, considerada como ponte inerte entre as mentes de seus produtores e observadores - ou mesmo, entre práticas e representações. As imagens, como buscamos apontar, não são, em si mesmas, objetos funcionais ou utilitários, servindo para isso ou para aquilo. Mas devem ser percebidas em relação com outras práticas sociais mais elaboradas ou abstratas, tal como a leitura quando se trata de produzir conhecimento.

Seria curioso perceber que a cultura visual da imagem do catolicismo foi capaz de transcender sua potência para além de suas fronteiras religiosas, ao passo que confirmariam o sentido das imagens gráficas de uma forma geral. Isto é, as imagens que circulam a nossa volta despertariam ainda a aparência de ser aquilo que seria a imagem na acepção antiga, como portadora de um sentido que outrora the foi atribuído, e que hoje se permitiria a lei natural do mundo como uma verdade ontológica, podendo esta atender a uma determinada ideologia ou ciência do saber, como no caso do Design.

No Ocidente a imagem nunca circularia de forma neutra, sem um propósito político pensado antes, como se pudesse supor o real em si mesmo uma verdade. Portanto, não teríamos clareza consciente, na maioria das vezes, de intuir suas motivações ideológicas ou políticas para a sua produção. Isto porque nos faltam as distinções sobre o que é imagem e sobre aquilo que parece ser apenas imagem. A própria imagem se tornou o acontecimento. Produzem-se imagens ao elaborar-se um fato em que apenas na imagem a sua verdade se tornaria realidade em si mesma e por si própria e se instituiria a favor da produção imagética. Seria impossível incriminar, seja quem for, aquele que suscita a idolatria e abusa das imagens, ao passo que os produtores de imagens também se tornaram anônimos. ${ }^{16}$ Isto em parte, pois seguramente os produtores de imagens, os donos dos meios de comunicação, tal como no catolicismo, possuem ainda hoje o domínio político sobre os efeitos dos códigos e dos meios de disseminação do material visual. Apesar de que essa

\footnotetext{
${ }^{15}$ BASCHET, Jérôme. L'iconographie médievale. Paris: Gallimard, 2008. pp. 26-28.

${ }^{16}$ Mencionaríamos aqui o caso das imagens "aparecidas", tal como a imagem da padroeira do Brasil, $\mathrm{N}$. S. da Conceição Aparecida, que foi "pescada" no rio Paraíba no início do século XVIII. A imagem não possui autoria, foi a própria divindade que a produziu e a ofertou aos pescadores.
} 
informação não ficaria tanto em evidência, pois nos dias de hoje a noção individualista instaurada de forma hegemônica, sugere que dentro das estruturas sociais cada indivíduo se comportaria a partir de sua própria ação individual de escolha e nunca coletiva como realmente é. Daí, ver tal ou tal imagem de modo autônomo é tido ou compreendido como uma opção individual e não controle político agenciado pelos produtores de imagens. De qualquer maneira apenas a nós mesmos é que acabamos dirigindo a censura da idolatria, pois já não seria possível encontrar ninguém que se comporte de maneira diferente, nem quem nos defendesse daqueles que as produzem.

Por outro lado, também seria falso afirmar que as imagens de outrora teriam simplesmente reproduzido o real e que este teria existido mesmo sem elas. Pelo contrário, se fossem observadas em sua história, elas participaram em tudo aquilo que em seu tempo se considerava real. ${ }^{17} \mathrm{E}$ essa participação consistiria a sua sugestão indispensável. A representação, nesse caso, viria a pressupor a existência do real, mas apenas traria a consciência quando o afirmasse e o tornasse descritível. Isso porque as criações ou até mesmo as construções imagéticas, que são elaboradas mentalmente, estariam relacionadas diretamente com a realidade do espaço, do mundo. Não haveria possibilidade de perceber ou conceber uma imagem, seja ela mental ou gráfica, que não estivesse de acordo com a estrutura social na qual fomos criados, ou melhor, do modo como fomos educados a ver. Afinal, nós apenas conseguimos associar e visualizar imagens pelo fato de estarmos socialmente inseridos. Caso contrário, não veríamos nada, ou melhor, visualizaríamos outra coisa, algo que estivesse de acordo com os nossos princípios representacionais visuais.

\section{REFERÊNCIAS}

BASCHET, Jérôme. L’iconographie médievale. Paris: Gallimard, 2008.

BELTING, Hans. A verdadeira imagem entre a fé e a suspeita das imagens: cenários históricos. Porto: Dafne, 2011.

BURKE, Peter. Testemunha ocular: história e imagem. Bauru: EDUSC, 2004.

GALLAO, Karl Georges. Santinhos: uma reflexão entre o design e os impressos religiosos populares. 2012. 140 f. Dissertação (mestrado) - Pontifícia Universidade Católica do Rio de Janeiro, Departamento de Artes e Design, 2012.

GRUZINSKI, Serge. A Guerra das imagens: de Cristóvão Colombo a Blade Runner (1492-2019). São Paulo: Companhia das Letras, 2006.

JÚNIOR, Oliveira. O Primeiro impressor português e sua obra. Porto, 1942. In.: SOARES, Ernesto. Retratos, in.: Museu, v. 4, n. 10: Porto, 1945. [BN: BA 3005 V].

LEITE, Ricardo de Souza. Ver é compreender: design como ferramenta estratégica de negócio. Rio de Janeiro: Editora Senac, 2003.

MÂLE, Émile. L'Art religieux du XIle siècle en France. Paris: Ernest Lerox, 1898. MARTIN, John Rupert. Baroque. New York: Harper \& Row, Publishers. 1977.

\footnotetext{
${ }^{17}$ BELTING, Hans. A verdadeira imagem entre a fé e a suspeita das imagens: cenários históricos. Porto: Dafne, 2011, p. 22.
} 